\title{
Increased Interleukin-17 Transcripts in Peripheral Blood Mononuclear Cells, a Link Between T-Helper 17 and Proinflammatory Responses in Bladder Cancer
}

\author{
Rasoul Baharlou ${ }^{1}$; Abdolaziz Khezri ${ }^{2,3}$; Mahboobeh Razmkhah ${ }^{3}$; Mojtaba Habibagahi ${ }^{4}$; \\ Ahmad Hosseini ${ }^{3}$; Abbas Ghaderi ${ }^{3,4}$; Mansooreh Jaberipour ${ }^{3, *}$ \\ ${ }^{1}$ Department of Immunology and Microbiology, Jahrom University of Medical Sciences, Jahrom, IR Iran \\ ${ }_{2}^{2}$ Department of Urology, Shiraz University of Medical Sciences, Shiraz, IR Iran \\ 3 Institute for Cancer Research, Shiraz University of Medical Sciences, Shiraz, IR Iran \\ ${ }^{4}$ Department of Immunology, Shiraz University of Medical Sciences, Shiraz, IR Iran \\ ${ }^{*}$ Corresponding Author: Mansooreh Jaberipour, Institute for Cancer Research, Shiraz University of Medical Sciences, Shiraz, IR Iran. Tel: +98-7112303687, +98-7112304952, E-mail: ja- \\ berim@sums.ac.ir
}

Received: November 29, 2012; Revised: August 14, 2013; Accepted: December 14, 2014

\begin{abstract}
Background: Interleukin (IL)-17-producing CD4+ T helper (Th17) cells thatare known by producing IL-17 have recently been defined as a unique subset of proinflammatory helper cells. IL-17 is an inflammatory cytokine with robust effect on many cells and it can play important roles in pathogenesis of diverse groups of immune-mediated diseases.

Objectives: The aim of this case-control study was to determine the gene expression of IL-6, IL-17, and transforming growth factor beta (TGF- $\beta$ ) in Iranian patients with bladder cancer.

Patients and Methods: Blood samples were collected from 37 patients with bladder cancer and 37 healthy individuals with no history of malignancies or autoimmune disorders, based of simple sampling. The expression of IL-6, IL-17, and TGF- $\beta$ were measured by quantitative real-time polymerase chain reaction (qRT-PCR).

Results: The mean of IL-17 transcripts was significantly higher in patients with bladder cancer compared with healthy individuals ( 0.33 \pm 0.06 vs. $0.42 \pm 0.14),(P=0.04)$, but their TGF- $\beta$ was lower $(12.53 \pm 8.41$ vs. $54.94 \pm 17.95),(P=0.04)$. However, the IL-6 transcripts level was similar in both groups $(5.34 \pm 2.40$ vs. $8.07 \pm 3.28),(\mathrm{P}>0.05)$ and there was not any significant difference between the noted cytokines expressions among patients with different stages and grades.

Conclusions: As most of the cases studied in this investigation were in stages I and II, IL-17 as a prominent proinflammatory cytokine may play an important role in recruiting and infiltrating of antitumor immune responses in early stages of bladder cancer. Furthermore, it can be used as predictor for the clinical stage and prognosis of cancers such as bladder carcinoma.
\end{abstract}

Keywords:Interleukin6; Interleukin17; Transforming Growth Factor Beta

\section{Background}

Two decades ago, Mossman and Coffman proposed that CD4 + T cells differentiate into two subsets with reciprocal functions and patterns of cytokine secretion, termed T-helper 1 (Th1) and Th2 (1). Th1 cells are characterized by production of interferon-g (IFN- $\gamma$ ) and induce cell-mediated immunity against intracellular pathogens, while Th2 cells produce interleukin-4 (IL-4) and stimulate humoral immunity against parasitic helminthes. This paradigm was maintained until 2005, when a third T-cell subset, known as Th17, was identified (2). IL-17 was reported with its major signature of releasing interleukin 17 (IL-17) (3). In recent years, growing reports on the role and function of Th17 indicate that this subset of CD4 + T cells plays a fundamental role in infiltration and recruitment of inflammatory cells against intercellular parasites and fungi (4). During tumor development, Th17 cells gradually increase in the tumor microenvironment. Many factors released by tumor cells and tumor stroma or molecules, secreted by tumor-infiltrating immune cells such as transforming growth factor (TGF- $\beta$ ), IL-6, prostaglandin E2 (PGE2), IL-21, IL-23, osteopontin, IL-1 $\beta$, and tumor necrosis factor alpha (TNF- $\alpha$ ) can play major roles in the induction of Th17 differentiation $(5,6)$. Several recent studies have demonstrated that TGF- $\beta$ and IL- 6 are critical factors for murine Th17 cell differentiation in vitro (7).

TGF- $\beta$ plays an essential role in differentiation of CD4 + $\mathrm{T}$ cells toward regulatory T cells (Tregs) or Th17 cells. The combination of TGF- $\beta$ and IL- 6 promotes the differentiation of Th17 cells and inhibits Treg cells differentiation in mice $(5,8)$, whereas TGF- $\beta$ plus retinoic acid inhibits Th17 cells differentiation and promotes the Treg cells $(9,10)$.

There are some studies that show the paradoxes of the protumor and antitumor functions of IL-17. Increased growth and proliferation of cervical cancer cells through IL-6 (11) increases blood vessels in ovarian cancer (12) and as a prognostic biomarker in colorectal cancer progres- 
sion have been noticed (13). On the other hand, antitumor functions of IL-17 have been reported. In this connection, Muranski et al. reported that Th17-polarized cells and release of IL-17 are more effective than Th1 cells in eliminating of established tumors (14). In addition, IL-17 has been shown to induce IL-6 from variety of cells. In fact, IL-17, via IL-6 and IL-12, is associated with the induction of tumor-specific cytotoxic T lymphocyte (CTL) induction (15), besides its effects on overexpression of major histocompatibility complex (MHC) classes I and II (16) and its role on dendritic cell maturation (17). Bladder cancer is one of the most common cancers in Iranian males (18). The importance of IL-17 in pathogenesis of bladder cancer is not fully identified.

\section{Objectives}

Due to the importance of IL-6, TGF- $\beta$ and IL-17 genes in bladder cancer disease, we used quantitative real-time polymerase chain (qRT-PCR) to directly measure their mRNA transcripts in peripheral blood cells of patients with bladder cancer compared with healthy blood donors.

\section{Patients and Methods}

\subsection{Subjects}

The participants in this case-control study were 37 patients, all with transitional cell carcinoma of bladder with mean age of $63 \pm 11$ years, confirmed by histological studies by urologists and pathologists, using simple sampling. The sample formula was as follows:

$$
\begin{aligned}
& \mathrm{N}=\left(\mathrm{Z}_{(1-\alpha \mid 2)}+\mathrm{Z}_{(1-\beta)}\right)^{2} \times\left(\delta_{1}^{2}+\delta_{2}^{2}\right) /\left(\mu_{1}-\mu_{2}\right)^{2}\left(\delta_{1}=2.2, \mu_{1}=4.3, \delta_{2}\right. \\
& \left.=1.1, \mu_{2}=5.5,1-\alpha / 2=1.96,1-\beta=0.84\right) .
\end{aligned}
$$

The patients were referred to our laboratory in the Institute for Cancer Research (ICR) as the cancer referral laboratory from the hospitals of Shiraz University of Medical Sciences, (Shiraz, Iran) during 2009-2010. Forty five patients provided their informed consents to take part in this study. Peripheral venous blood samples of $2 \mathrm{~mL}$ were collected by venipuncture before any clinical intervention. None of the patients had received chemotherapy, radiotherapy or immunotherapy before sampling and eight patients were excluded from study because of some technical errors. Data on age, tumor histology, tumor size, tumor invasion, clinical stage, histological grade, and presence of other organ metastases were obtained from the hospital pathological records of the patients. Theclinical stage was determined with the tumor-node-metastasis classification;primary tumor $(\mathrm{T} 1=$ tumor invades the sub-epithelial connective tissue, $\mathrm{T} 2$ = tumor invades the muscle, $\mathrm{T} 3$ = tumor invades the perivesical tissue, and T4 $=$ tumor invades the prostate, uterus or vagina and the pelvic wall or the abdominal wall), lymph nodes (N1 = involvement in a single lymph node $2 \mathrm{~cm}$ or less in greatest dimension, N2 = Involvement in a single lymph node 2-5 $\mathrm{cm}$, and N3 = involvement in a lymph node more than 5 $\mathrm{cm})$, and metastasis ( $\mathrm{MO}=$ no metastasis and M1= metasta- sis). The tumor, lymph node, metastasis (TNM) classification and tumor diameter were obtained from the pathology reports by one pathologist. In addition, the tumors were graded according to the World Health Organization (WHO) classification criteria as moderately or poorly differentiated. Table 1 demonstrates the distribution of patients regarding different clinical criteria. The patients with high-grade and metastatic bladder cancer comprised a small group and statistically were not able to be compared with low-grade and non-metastatic patients.

Table 1. Distribution of Patients With Bladder Cancer With

\begin{tabular}{|c|c|}
\hline Pathological Characteristic & Frequency, No. (\%) \\
\hline \multicolumn{2}{|l|}{ Gender } \\
\hline Male & $26(70)$ \\
\hline Female & $11(30)$ \\
\hline \multicolumn{2}{|l|}{ Lymphatic Invasion } \\
\hline Positive & $12(32)$ \\
\hline Negative & $28(68)$ \\
\hline \multicolumn{2}{|l|}{ Vascular Invasion } \\
\hline Positive & $18(49)$ \\
\hline Negative & $22(51)$ \\
\hline \multicolumn{2}{|l|}{ Preneural Invasion } \\
\hline Positive & $7(19)$ \\
\hline Negative & $33(81)$ \\
\hline \multicolumn{2}{|l|}{ Prostate Invasion } \\
\hline Positive & $16(43)$ \\
\hline Negative & $21(57)$ \\
\hline \multicolumn{2}{|l|}{ Seminal Invasion } \\
\hline Positive & $2(5)$ \\
\hline Negative & $35(95)$ \\
\hline \multicolumn{2}{|l|}{ Muscular Invasion } \\
\hline Positive & $13(35)$ \\
\hline Negative & $24(65)$ \\
\hline \multicolumn{2}{|l|}{ Grade } \\
\hline Low & $17(46)$ \\
\hline High & $20(54)$ \\
\hline \multicolumn{2}{|l|}{ Stage } \\
\hline I & $14(38)$ \\
\hline IIb & $5(13)$ \\
\hline IIc & $10(27)$ \\
\hline III & $4(11)$ \\
\hline IV & $4(11)$ \\
\hline \multicolumn{2}{|l|}{ Metastasis } \\
\hline Positive & $4(11)$ \\
\hline Negative & $33(89)$ \\
\hline
\end{tabular}
Regard to Different Clinical Criteria 
Baharlou Ret al.

Blood samples from 37 healthy individuals with mean age of $61 \pm 3$ years without history of malignancies or autoimmune disorders were also obtained as control group. During sample collection, it was ensured that subjects had neither infection nor any acute or chronic disease. During data analysis, 13 of 15 samples were excluded. All the subjects provided informed consents to participate in the study and to allow their biological samples to be analyzed. Approval for the study was given by the Ethics Committee of the Shiraz University of Medical Sciences (Shiraz, Iran).

\subsection{RNA Isolation and cDNA Synthesis}

Total RNA was prepared from the blood cells after lysis with ammonium chloride and TRizol reagent (Invitrogen, Paisley, UK). For cDNA synthesis, RNA was treated with DNase I (Invitrogen-Gibco, Paisley, UK) to avoid DNA contamination, then cDNA was synthesized from $5 \mu \mathrm{g}$ of the total RNA, using the Revert Aid First Strand cDNA Synthesis Kit (Fermentas, Vilnius, Lithuania).

\subsection{Quantitative Real-Time RT-PCR}

The abundance of IL-6, TGF- $\beta$ and IL-17 genes transcripts was determined by qRT-PCR, using a Bio-Rad system (Chromo4 RT PCR Detector, Bio-Rad, Foster City, CA, USA) with SYBR Green PCR master mix kit (Applied Biosystems, Foster City, CA, USA). Expression of $\beta$-actin housekeeping gene was used as a reference for the level of target gene expression. Each PCR reaction was performed in a final volume of $25 \mu \mathrm{L}$ and contained $0.5 \mu \mathrm{g}$ of the cDNA product, $4.0 \mathrm{pmol}$ of each primer, and $1 \mathrm{x}$ reaction mixture, consisting of Fast Start DNA polymerase, reaction buffer, dNTPs, and SYBR green I. Table 2 shows the forward and reverse primers for $\beta$-actin, IL-6, TGF- $\beta$ and IL-17 genes. The primers were designed using primer 3 open-source software (Source forge, USA). Thermal cycling for all the genes was initiated with a denaturation step at $95^{\circ} \mathrm{C}$ for $10 \mathrm{~min}$ utes, followed by 40 cycles (denaturation at $95^{\circ} \mathrm{C}$ for 15 seconds, annealing at $56^{\circ} \mathrm{C}$ for 30 seconds, and extension at $60^{\circ} \mathrm{C}$ for 60 seconds when fluorescence appeared). The qRT-PCR amplification products were analyzed by melting curve analysis. Meanwhile, all the data were analyzed for calibrated equipment.

\subsection{Statistical Analysis}

The amounts of IL-6, TGF- $\beta$ and IL-17 genes transcripts in the peripheral blood was compared to the correspond- ing values from the control samples using nonparametric Mann-Whitney test by SPSS software v.15. The relative amounts of IL-6, TGF- $\beta$ and IL-17 transcripts were determined using $2^{-\Delta \Delta c t}$ formula. The Target-to-reference gene ratios were calculated using Pfaffl method (19). Finally, correlations between different cell populations were evaluated using Spearman's rank correlation coefficient. Relative expression was plotted and evaluated by means of Prism 5 software (San Diego, CA, USA, 2003). P $<0.05$ was regarded as significant in all the statistical analyses.

\section{Results}

\subsection{Gene Expression of Cytokines in Whole Blood Samplesof Patient and Healthy Controls}

The gene expression of IL-6 in peripheral blood mononuclear cells was examined using mRNA analysis. The Expressions of the IL- 6 gene transcripts in all the patients with bladder cancer, early-stage, low-grade and non-metastatic patients were not different compared with the control group ( $\mathrm{P}>0.05)$, Figure 1. However, there was a significant correlation between IL-6 and preneural inva$\operatorname{sion}(P=0.004, r=0.47)$ (data is not shown).

As shown in Figure 2, specimens in the control group expressed substantially higher levels of IL-6 than all the patients $(P=0.03)$, Table 3 . In addition, among the patients in early disease stages (stages I and II), low-grade and non-metastasis status, the gene expression of IL- 6 was less compare to healthy volunteers $(P=0.03,0.03$ and 0.04 , respectively). In addition, there was a significant correlation between the level of IL-6 and preneural invasion $(\mathrm{P}=0.01, \mathrm{r}=0.41)$ (data not shown).

The IL-17 gene expression showed a significantly higher level among patients compared with the control group $(\mathrm{P}=0.04)$. Remarkably, patients in early-stage and nonmetastatic statuses of the disease showed significant differences in the mean relative IL-17 expression ( $\mathrm{P}=0.05$ and 0.02 , respectively), Figure 3. Although the gene expression of IL-17 in patients with a low-grade of the disease was higher than the control group, there was no significant difference between them $(P=0.07)$, Table 3. We noted significant correlations of IL-17 gene expression with preneural invasion $(\mathrm{P}=0.01, \mathrm{r}=0.42)$, seminal invasion $(P=0.0002, r=0.69)$, grade $(P=0.03, r=0.34)$, and stage $(\mathrm{P}<0.0001, \mathrm{r}=0.61)$ (data not shown). These results are summarized in Table 4 .

Table 2. Forward and Reverse Primers of $\beta$-Actin, IL-6, TGF- $\beta$, and IL-17 Genes for Real-Time PCR Amplification

\begin{tabular}{lc}
\hline Primers & \multicolumn{1}{c}{ Sequence } \\
\hline $\boldsymbol{\beta}$-actin forward; $\boldsymbol{\beta}$-actin, reverse & 5' ACAGAGCCTCGCCTTTGCCG 3',5' CACCATCACGCCCTGGTGCC 3' \\
\hline IL-17, forward; IL-17, reverse & 5' GGACTGTGATGGTCAACCTG 3',5' CTCCCAGATCACAGAGGGAT 3' \\
IL-6, forward; IL-6 reverse & 5' CAGGTTGTTTTCTGCCAGTG 3',5' GACCGACACTCACCTCTTCA 3' \\
TGF- $\boldsymbol{\beta}$, forward; TGF- $\boldsymbol{\beta}$, reverse & 5' TGGTTGAGCCGTGGAGGGGA 3',5' CTCGGCGGCCGGTAGTGAAG 3' \\
\hline
\end{tabular}


Baharlou R et al.

\begin{tabular}{|c|c|c|c|c|c|c|c|c|c|}
\hline & \multicolumn{3}{|c|}{ IL-6 } & \multicolumn{3}{|c|}{ TGF- $\beta$} & \multicolumn{3}{|c|}{ IL-17 } \\
\hline & Mean \pm SEM & Median & $\mathbf{P}$ & Mean \pm SEM & Median & $\mathbf{P}$ & Mean \pm SEM & Median & $\mathbf{P}$ \\
\hline $\operatorname{Controls}(\mathbf{n}=37)$ & $8.07 \pm 3.28$ & 1.26 & & $54.94 \pm 17.95$ & 0.10 & & $0.42 \pm 0.14$ & 0.08 & \\
\hline All the patients $(n=37)$ & $5.34 \pm 2.40$ & 0.98 & $>0.05$ & $12.53 \pm 8.41$ & 0.05 & 0.03 & $0.33 \pm 0.06$ & 0.25 & 0.04 \\
\hline Early-stage $(n=29)$ & $5.39 \pm 2.97$ & 0.89 & $>0.05$ & $12.08 \pm 7.71$ & 0.04 & 0.03 & $0.87 \pm 0.38$ & 0.26 & 0.05 \\
\hline Low grade $(n=17)$ & $5.51 \pm 3.85$ & 0.89 & $>0.05$ & $5.08 \pm 1.89$ & 0.03 & 0.03 & $0.83 \pm 0.08$ & 0.24 & 0.07 \\
\hline Non-metastatic $(n=33)$ & $5.84 \pm 2.69$ & 0.95 & $>0.05$ & $10.53 \pm 6.74$ & 0.05 & 0.04 & $0.82 \pm 0.32$ & 0.29 & 0.02 \\
\hline
\end{tabular}

\footnotetext{
a Relative expression of the gene of interest/ $\beta$-actin.

$\mathrm{b}$ The presented data was analyzed with the nonparametric two-tailed Mann-Whitney test. Early-stage patients were in stages I and II with a localized tumor in bladder and low-grade patients were in grades 1 and 2 with a well or moderate differentiation.
}

Table 4. Gene Expression of IL-6, TGF- $\beta$ and IL-17 in Different Clinic Pathological Parameters of Patients With Bladder Cancer ${ }^{\text {a }}$

\begin{tabular}{|c|c|c|c|c|c|c|c|c|c|}
\hline & \multicolumn{3}{|l|}{ IL-6 ${ }^{b}$} & \multicolumn{3}{|c|}{ TGF- $\beta$ b } & \multicolumn{3}{|c|}{ IL-17 ${ }^{\mathrm{b}}$} \\
\hline & Mean \pm SEM & Median & $\mathbf{P}$ & Mean \pm SEM & Median & $\mathbf{p}$ & Mean \pm SEM & Median & $\mathbf{P}$ \\
\hline \multicolumn{10}{|l|}{ Gender } \\
\hline Male & $6.27 \pm 2.95$ & 0.77 & NS & $12.35 \pm 9.02$ & 0.06 & NS & $2.12 \pm 0.99$ & 0.29 & NS \\
\hline Female & $4.66 \pm 1.97$ & 1.05 & & $4.55 \pm 1.64$ & 0.05 & & $0.44 \pm 0.12$ & 0.42 & \\
\hline \multicolumn{10}{|c|}{ Lymphatic invasion } \\
\hline Negative & $5.27 \pm 2.54$ & 0.74 & NS & $11.7 \pm 8.20$ & 0.04 & NS & $0.77 \pm 0.36$ & 0.24 & NS \\
\hline Positive & $8.92 \pm 5.49$ & 2.20 & & $2.60 \pm 0.82$ & 0.05 & & $6.17 \pm 3.98$ & 3.80 & \\
\hline \multicolumn{10}{|c|}{ Vascular invasion } \\
\hline Negative & $5.07 \pm 2.21$ & 0.70 & NS & $6.50 \pm 3.28$ & 0.05 & NS & $1.01 \pm 0.41$ & 0.29 & NS \\
\hline Positive & $6.99 \pm 4.51$ & 0.84 & & $13.65 \pm 14.76$ & 0.04 & & $2.56 \pm 1.69$ & 0.38 & \\
\hline \multicolumn{10}{|c|}{ Preneural invasion } \\
\hline Negative & $5.19 \pm 1.72$ & 0.77 & NS & $9.75 \pm 6.56$ & 0.05 & NS & $1.46 \pm 0.77$ & 0.27 & NS \\
\hline Positive & $12.26 \pm 7.09$ & 1.55 & & $2.60 \pm 0.82$ & 0.04 & & $2.27 \pm 1.80$ & 0.70 & \\
\hline \multicolumn{10}{|c|}{ Prostate invasion } \\
\hline Negative & $6.95 \pm 3.20$ & 1.45 & NS & $14.95 \pm 9.84$ & 0.06 & NS & $1.13 \pm 0.52$ & 0.38 & NS \\
\hline Positive & $6.47 \pm 5.90$ & 0.62 & & $1.95 \pm 0.82$ & 0.01 & & $4.39 \pm 2.98$ & 0.55 & \\
\hline \multicolumn{10}{|c|}{ Muscular invasion } \\
\hline Negative & $3.82 \pm 1.31$ & 0.71 & NS & $15.6 \pm 11.48$ & 0.03 & NS & $1.01 \pm 0.53$ & 0.15 & NS \\
\hline Positive & $8.72 \pm 4.35$ & 1.55 & & $2.60 \pm 0.82$ & 0.05 & & $2.46 \pm 1.53$ & 0.48 & \\
\hline \multicolumn{10}{|l|}{ Tumor size } \\
\hline$<5 \mathrm{~cm}$ & $5.47 \pm 2.38$ & 0.80 & NS & $9.10 \pm 6.56$ & 0.04 & NS & $0.88 \pm 0.56$ & 0.29 & NS \\
\hline$\geq 5 \mathrm{~cm}$ & $6.99 \pm 4.92$ & 1.35 & & $13.65 \pm 13.12$ & 0.06 & & $2.06 \pm 0.97$ & 0.13 & \\
\hline \multicolumn{10}{|l|}{ Grade } \\
\hline Low & $5.51 \pm 3.85$ & 0.89 & NS & $5.08 \pm 1.89$ & 0.03 & NS & $0.83 \pm 0.08$ & 0.24 & NS \\
\hline High & $5.99 \pm 2.46$ & 1.01 & & $5.85 \pm 3.28$ & 0.05 & & $2.35 \pm 1.29$ & 0.38 & \\
\hline \multicolumn{10}{|l|}{ Stage } \\
\hline Early & $5.39 \pm 2.97$ & 0.89 & NS & $12.08 \pm 7.71$ & 0.04 & NS & $0.87 \pm 0.38$ & 0.26 & NS \\
\hline Late & $7.92 \pm 4.84$ & 2.01 & & $2.60 \pm 0.82$ & 0.05 & & $0.97 \pm 0.58$ & 0.38 & \\
\hline \multicolumn{10}{|l|}{ Metastasis } \\
\hline Negative & $5.84 \pm 2.69$ & 0.95 & NS & $10.53 \pm 6.74$ & 0.05 & NS & $0.82 \pm 0.32$ & 0.29 & NS \\
\hline Positive & $5.43 \pm 7.38$ & 0.46 & & $1.95 \pm 0.82$ & 0.02 & & $1.26 \pm 1.04$ & 0.29 & \\
\hline
\end{tabular}

\footnotetext{
a Abbreviation: NS: notsignificant.

$\mathrm{b}$ Relative expression of the gene of interest $/ \beta$-actin.
} 
Figure 1. Expression Level of IL-6 in Peripheral Blood Cells of Patients With Bladder Cancer and Normal Individuals

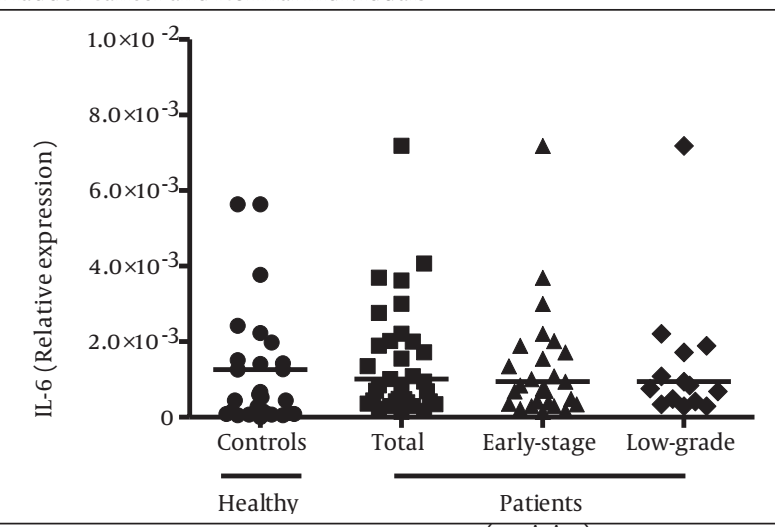

The presented data was calculated with the $2(-\Delta \Delta \mathrm{ct})$ formula.The horizontal bars indicate median values. No significant difference was found in IL-6 mRNA expression among all the patients with early-stage (I, II) lowgrade and non-metastatic disease compared to healthy controls $(\mathrm{P}>0.05)$.

Figure 2. TGF- $\beta$ Gene Transcripts in Peripheral Blood Cells of Patients With Bladder Cancer and Healthy Controls

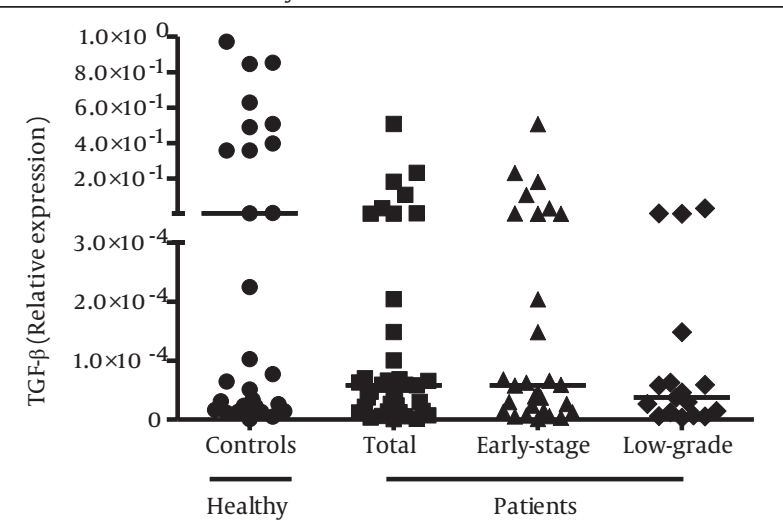

Data was calculated with the $2^{(-\Delta \Delta \mathrm{ct})}$ formula. The horizontal bars indicate the median values. Significant differences were found in levels of TGF- $\beta$ expression among the patients with total, early-stage (I, II) lowgrade, and non-metastatic bladder cancer compared to healthy controls

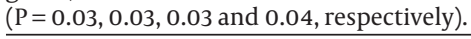

Figure 3. Expression Level of IL-17 in the Peripheral Blood Cells of Patients With Bladder Cancer and Normal Controls

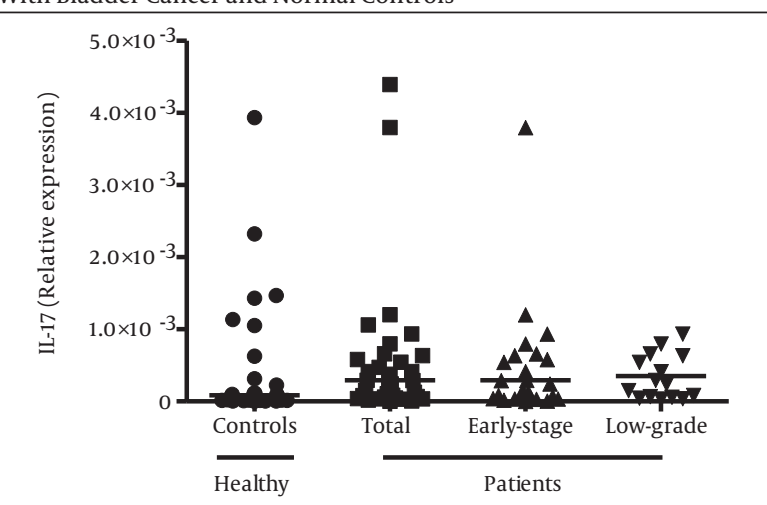

Data was calculated similar to Figures 1 and 2. The horizontal bars indicate the median values. Significant differences were found in levels of IL-17 expression among all the patients, early-stage (I, II), and non-metastatic ( $\mathrm{P}$ $=0.04,0.05$ and 0.02 , respectively), but in none of the patients with lowgrade bladder cancer, compared to healthy controls $(\mathrm{P}=0.07)$.

\section{Discussion}

Current understanding of IL-17 is that it plays an important role in inflammation and it is critical in host defense against infectious disease,allergy and autoimmunity (20, 21). Although TGF- $\beta$ induces T regulatory cells, the combination of TGF- $\beta$ and IL-6 instruct T cells to differentiate into Th17 cell (7). In addition to its important physiological roles, Th17 may involve in cancer and autoimmunity. Therefore, in this study, we evaluated the IL-17 transcripts as hallmarks of Th17 cells, as well as TGF- $\beta$ and IL- 6 transcripts as the cytokines inducing Th17 cells differentiation, in peripheral blood cells of patients with bladder cancer. Our data indicated a higher expression of IL-17, but not IL-6, in patients compared to controls. However, TGF- $\beta$ expression was vice versa. The mRNA expression of IL-17 was investigated by Zhang et al. who detected increased expression levels of IL-17 and IL-23 mRNA in tumor tissues from patients with gastric cancer, suggesting that Th17 cells differentiation may increasein gastric cancer (22). Wang et al. reported that disruption of IL-17 dramatically reduced tumorigenesis in this model in a manner correlated with diminished STAT3 activation intumor microenvironment (19). Doroudchi's findings showed that IL17 was elevated in lower stages (I and II) compared with higher stages (III and IV) of bladder cancer and it can be an important factor in the inflammatory process during tumor progression, either as a defense mechanism or as a tumor-promoting factor (23). There are other studies showing that IL-17 and IL-21 increase in gastric and oral squamous cell carcinomas, which suggest these cytokines as therapeutic targets for treatment of cancer $(24,25)$.

Kryczek and colleagues, however, demonstrated a protective role of IL-17 in tumor immunity (26). They also revealed that Th17 cells may contribute to protective human tumor immunity through inducing Th1-type chemokines and recruiting the effector cells to the tumor microenvironment and they play an indirect role in antitumor immunity by promoting the effector CD8 + T cells (27). Jaberipour et al. showed IL-17 and IL- 6 transcripts as proinflammatory responses which are increased in PBMCs, which can be vital in early stages of cancers (28). Chen et al. emphasized that tumor growth and invasive capability were attenuated when IL- 6 was blocked. Their findings show that IL- 6 can be a significant predictor for the clinical stage and prognosis of bladder cancer (29).

All these data attempt to show and to prove that IL-17, a multifunctional cytokine, has the capability to promote tumor growth and expansion. The Th17 cells can be considerable in two approaches; an important aspect thatrequires to be considered with care in relation to the functional activity of Th17 and the emergence of IL-17 is the reciprocal effect of $T$ regulatory cells with Th17 in modification and regulation of the balance between the anti-inflammatory and inflammatory immune responses (9, 30, 31). Accordingly, our finding of the increased expression of IL-17 in PBMCs in patients with early stages of bladder can- 
cer can be interpreted as a reflection of a protective proinflammatory response which recruits the immune cells to the site of early tumor in bladder. However, proinflammatory responses are double-edged sword with protective and tumorgenesis roles $(32,33)$. With cancer progression, especially in the late stage, as a result of pressure by tumor cells and release of a lot of self-antigens, an increased Treg cells state occurs (21). It may cause to convert a proinflammatory response into an anti-inflammatory condition, resulting in disease deterioration. According to this hypothesis, one can suggest that the best time for immunotherapy approaches is in the early stages of cancer, where the immune system has not been under pressure neither by tumor side nor by immunosuppression induced by $\mathrm{T}$ regulatory cells. TGF- $\beta$ can be released by tumor and T regulatory cells during the late stages of most of the solid cancers $(34,35)$. Since we observed reduced TGF- $\beta$ expressionin our findings, it means that a patient's immune system in the early stage of bladder cancer is still enough competent and has not been influenced by the actions of $T$ regulatory suppression. If these findings get confirmed in a larger sample sizes, a suitable window period based on detection of these cytokines for immune manipulation of bladder cancer can be obtained.

As the presented data was in line with our previous study onbreast cancer (28), it can be concluded that increased IL-17 and reduced TGF- $\beta$ gene expressions in patients with the early-stage of cancer, spot a vigorous proinflammatory reaction by the immune system against cancer. Therefore, along with increased TGF- $\beta$ in the late stage of cancer, angiogenic factors cause cancer deterioration. Therefore, the current cytokine profile can beclinically used as marker in detection of early stages of tumor for better medical actions for prevention of tumor deterioration. In addition, it is suggested that antitumor immunotherapy in early stages of the disease may delay the immunosuppression effects induced by the Treg cells. It is suggested that for covering theweak points of the current study, Th1/ Th2/ Th17/ Treg cytokine profiles would be assessed simultaneously and with larger samples.

\section{Acknowledgements}

The authors thank thepatients with bladder cancer as well as the normal individuals for their kind participation in this project.

\section{Funding/Support}

This work was financially supported by a grant from Shiraz Institute for Cancer Research (ICR-100-505) (www. icr.ir100-505) and Shiraz University of Medical Sciences (Grant No. 88-4867).

\section{References}

1. Murphy KM, Reiner SL. The lineage decisions of helper T cells. Nat Rev Immunol. 2002;2(12):933-44.

2. Harrington LE, Hatton RD, Mangan PR, Turner H, Murphy TL,
Murphy KM, et al. Interleukin 17-producing CD4+ effector T cells develop via a lineage distinct from the Thelper type 1 and 2 lineages. Nat Immunol. 2005;6(11):1123-32.

3. Xu S, Cao X. Interleukin-17 and its expanding biological functions. Cell Mol Immunol. 2010;7(3):164-74.

4. Peck A, Mellins ED. Breaking old paradigms: Th17 cells in autoimmune arthritis. Clin Immunol. 2009;132(3):295-304.

5. Nam JS, Terabe M, Kang MJ, Chae H, Voong N, Yang YA, et al. Transforming growth factor beta subverts the immune system into directly promoting tumor growth through interleukin-17. Cancer Res. 2008;68(10):3915-23.

6. Shime H, Yabu M, Akazawa T, Kodama K, Matsumoto M, Seya T, et al. Tumor-secreted lactic acid promotes IL-23/IL-17 proinflammatory pathway.J Immunol. 2008;180(11):7175-83.

7. Zhou Z, Sun W, Liang Y, Gao Y, Kong W, Guan Y, et al. Fenofibrate inhibited the differentiation of T helper 17 cells in vitro. PPAR Res. 2012;2012:145654.

8. Passos ST, Silver JS, O'Hara AC, Sehy D, Stumhofer JS, Hunter CA. IL-6 promotes NK cell production of IL-17 during toxoplasmosis. $J$ Immunol. 2010;184(4):1776-83.

9. Mucida D, Cheroutre H. TGFbeta and retinoic acid intersect in immune-regulation. Cell Adh Migr. 2007;1(3):142-4.

10. Mucida D, Park Y, Kim G, Turovskaya O, Scott I, Kronenberg M, et al. Reciprocal TH17 and regulatory $\mathrm{T}$ cell differentiation mediated by retinoic acid. Science. 2007;317(5835):256-60.

11. Wang L, Yi T, Kortylewski M, Pardoll DM, Zeng D, Yu H. IL-17 can promote tumor growth through an IL-6-Stat3 signaling pathway. JExp Med. 2009;206(7):1457-64.

12. Kato T, Furumoto H, Ogura T, Onishi Y, Irahara M, Yamano S, et al. Expression of IL-17 mRNA in ovarian cancer. Biochem Biophys Res Commun. 2001;282(3):735-8.

13. Radosavljevic G, Ljujic B, Jovanovic I, Srzentic Z, Pavlovic S, Zdravkovic N, et al. Interleukin-17 may be a valuable serum tumor marker in patients with colorectal carcinoma. Neoplasma. 2010;57(2):135-44.

14. Muranski P, Boni A, Antony PA, Cassard L, Irvine KR, Kaiser A, et al. Tumor-specific Th17-polarized cells eradicate large established melanoma. Blood. 2008;112(2):362-73.

15. Jovanovic DV, Di Battista JA, Martel-Pelletier J, Jolicoeur FC, He Y, Zhang M, et al. IL-17 stimulates the production and expression of proinflammatory cytokines, IL-beta and TNF-alpha, by human macrophages. JImmunol. 1998;160(7):3513-21.

16. Hirahara N, Nio Y, Sasaki S, Minari Y, Takamura M, Iguchi C, et al. Inoculation of human interleukin-17 gene-transfected Meth-A fibrosarcoma cells induces T cell-dependent tumor-specific immunity in mice. Oncology. 2001;61(1):79-89.

17. Antonysamy MA, Fanslow WC, Fu F, Li W, Qian S, Troutt AB, et al. Evidence for a role of IL-17 in organ allograft rejection: IL-17 promotes the functional differentiation of dendritic cell progenitors. J Immunol. 1999;162(1):577-84.

18. Kolahdoozan S, Sadjadi A, Radmard AR, Khademi H. Five common cancers in Iran. Arch Iran Med. 2010;13(2):143-6.

19. Wang L, Yi T, Zhang W, Pardoll DM, Yu H. IL-17 enhances tumor development in carcinogen-induced skin cancer. Cancer Res. 2010;70(24):10112-20.

20. Park H, Li Z, Yang XO, Chang SH, Nurieva R, Wang YH, et al. A distinct lineage of CD4 T cells regulates tissue inflammation by producing interleukin 17. Nat Immunol. 2005;6(11):1133-41.

21. Hsu HC, Yang P, Wang J, Wu Q, Myers R, Chen J, et al. Interleukin 17-producing T helper cells and interleukin 17 orchestrate autoreactive germinal center development in autoimmune BXD2 mice. Nat Immunol. 2008;9(2):166-75.

22. Zhang JP, Yan J, Xu J, Pang XH, Chen MS, Li L, et al. Increased intratumoral IL-17-producing cells correlate with poor survival in hepatocellular carcinoma patients. J Hepatol. 2009;50(5):980-9.

23. Doroudchi M, Saidi M, Malekzadeh M, Golmoghaddam H, Khezri A, Ghaderi A. Elevated IL-17A levels in early stages of bladder cancer regardless of smoking status. Future Oncol. 2013;9(2):295-304.

24. Iida T, Iwahashi M, Katsuda M, Ishida K, Nakamori M, Nakamura $\mathrm{M}$, et al. Tumor-infiltrating CD4+ Th17 cells produce IL-17 in tumor microenvironment and promote tumor progression in human gastric cancer. Oncol Rep. 2011;25(5):1271-7.

25. Lee JJ, Chang YL, Lai WL, Ko JY, Kuo MY, Chiang CP, et al. Increased 


\section{Baharlou Ret al.}

prevalence of interleukin-17-producing CD4(+) tumor infiltrating lymphocytes in human oral squamous cell carcinoma. Head Neck. 2011;33(9):1301-8.

26. Kryczek I, Wei S, Szeliga W, Vatan L, Zou W. Endogenous IL-17 contributes to reduced tumor growth and metastasis. Blood. 2009;114(2):357-9.

27. Kryczek I, Banerjee M, Cheng P, Vatan L, Szeliga W, Wei S, et al. Phenotype, distribution, generation, and functional and clinical relevance of Th17 cells in the human tumor environments. Blood. 2009;114(6):1141-9.

28. Jaberipour M, Baharlou R, Hosseini A, Talei A, Razmkhah M, Ghaderi A. Increased il-17 and il-6 transcripts in peripheral blood mononuclear cells: Implication for a robust proinflammatory response in early stages of breast cancer. MEJC. 2011;2(1):19-26.

29. Chen MF, Lin PY, Wu CF, Chen WC, Wu CT. IL-6 expression regulates tumorigenicity and correlates with prognosis in bladder cancer. PLoS One. 2013;8(4).

30. Weaver CT, Hatton RD. Interplay between the TH17 and TReg cell lineages: a (co-)evolutionary perspective. Nat Rev Immunol. 2009;9(12):883-9.

31. Yang L, Qi Y, Hu J, Tang L, Zhao S, Shan B. Expression of Th17 cells in breast cancer tissue and its association with clinical parameters. Cell Biochem Biophys. 2012;62(1):153-9.

32. Khatami M. Inflammation, aging, and cancer: tumoricidal versus tumorigenesis of immunity: a common denominator mapping chronic diseases. Cell Biochem Biophys. 2009;55(2):55-79.

33. Erdman SE, Poutahidis T. Roles for inflammation and regulatory T cells in colon cancer. Toxicol Pathol. 2010;38(1):76-87.

34. Guo W, Dong Z, Guo Y, Chen Z, Yang Z, Kuang G, et al. Polymorphisms of transforming growth factor-beta1 associated with increased risk of gastric cardia adenocarcinoma in north China.Int J Immunogenet. 2011;38(3):215-24.

35. Chizzolini C, Chicheportiche R, Alvarez M, de Rham C, RouxLombard P, Ferrari-Lacraz S, et al. Prostaglandin E2 synergistically with interleukin-23 favors human Th17 expansion. Blood. 2008;112(9):3696-703. 